\title{
AUDITING THE CESAREAN SECTION RATE BY ROBSON'S TEN GROUP CLASSIFICATION SYSTEM AT TERTIARY CARE HOSPITAL.
}

\footnotetext{
1. MBBS, FCPS

Senior Registrar Obstetrician \& Gynecology KRL) hospital, Islamabad.

2. MBBS, FCPS

Professor Gynecology $\mathrm{KRL}$ ) hospital, Islamabad.

3. MBBS, FCPS

Senior Registrar Gynecology

$\mathrm{KRL}$ ) hospital, Islamabad.
}

Correspondence Address: Dr. Mehak Aslam Khan House No. 227, Street Num 13

E-11/4, NPF, Islamabad.

unsolved-enigma@hotmail.com

Article received on:

06/03/2019

Accepted for publication:

$16 / 07 / 2019$

\begin{abstract}
Mehak Asim Khan ${ }^{1}$, Irum Sohail ${ }^{2}$, Maria Habib ${ }^{3}$
ABSTRACT... Objectives: To analyze the trends of cesarean sections, categorize them into Robson's Ten Group Classification System (RTGCS), to identify the groups contributing the most to overall lower segment cesarean section (LSCS) rate and to formulate strategies for reducing these rates. Study Design: Cross sectional study. Setting: Gynecology and Obstetrics Department of Kahuta Research Laboratories (KRL) hospital, Islamabad. Period: From $1^{\text {st }}$ Nov, 2017 to $30^{\text {th }}$ April, 2018. Material \& Methods: The births during this period were distributed into the RTGCS on the basis of past obstetric history and fetal characteristics along with mode of onset of labour. Overall LSCS rate was calculated and contribution of each group was analyzed separately by SPSS version 23. Results: Our study showed 617 LSCS out of 964 deliveries making a high LSCS rate of $64 \%$. Group 5, 2 and 10 of RTGCS contributed to the majority of LSCS performed with the percentages of $47.5 \%, 18.5 \%$ and $12.8 \%$ respectively. Group 5 of RTGCS which contributed to the highest LSCS rate had 354 subjects which were previous scars out of which 199 had previous 1 scar making the percentage $56.21 \%$. It contributed $32.3 \%$ to the overall LSCS rate. Conclusion: RTGCS is a very useful tool for auditing the LSCS rate at local, national and international levels. Once the LSCS are classified into specific RTGCS, analysis can be done about the reasons for the increasing rates of LSCS and then strategies can be devised to reduce them.
\end{abstract}

Key words: $\quad$ Audit, Cesarean Section, Robson's Ten Group Classification System, RGTCS.

Article Citation: Khan MA, Sohail I, Habib M. Auditing the cesarean section rate by robson's ten group classification system at tertiary care hospital. Professional Med J 2020; 27(4):700-706. DOI: 10.29309/TPMJ/2020.27.04.3383

\section{INTRODUCTION}

William an obstetrician in chief at John Hopkins University in 1931 stated that "the excellence of an obstetrician should be judged not by the number of cesareans which he performs but rather by those which he does not do." To date this stands true and to achieve a low LSCS rate much have been said and done.

There were times in USA when for several decades the rate remained between $4-6 \%$ but between 1968 to 1978 the rate tripled to $15.2 \%$. In 1981 National Institute of Health expressed concern about rising LSCS rate and for the first time recommendations for reducing LSCS by vaginal birth after cesarean (VBAC) were promoted. ${ }^{2}$ Later by Year 2000, a 15\% LSCS rate as a US health promotion objective was given. ${ }^{3}$
Simultaneously WHO also concluded that there was no justification for any region to have a LSCS rate higher than $10-15 \% .{ }^{4}$ This rate was a clear indicator of good maternal and neonatal outcome in European countries. However, from the beginning of this millennium, a significant increase in this rate was observed worldwide. ${ }^{5} \mathrm{~A}$ rate of $30 \%$ was documented in some countries. By the year 2011, 1 in 3 women gave birth by cesarean deliveries. ${ }^{6}$

As these rates started to increase, many obstetricians became alarmed across the globe to revisit the factors which were key responsible for its rise. It was observed that indications for primary LSCS were mostly labour dystocia, nonreassuring fetal heart rate tracing and suspected fetal macrosomia. ${ }^{7}$ A new indication of maternal request was added to the above list and $a$ 
frequency of $3 \%$ was seen in 2011 in USA, while in India, in the same year, it was $29 \%{ }^{8}$

The absence of a universally accepted classification for LSCS to analyze the trends and to monitor the rates remains the biggest hurdle in understanding the reasons for increase in LSCS rates. A systemic review in 2011 inferred that amongst the different classifications available RTGCS could be used to meet the global requirements. It was stressed upon that attempts to develop a standardized classification be made on developing this classification further. ${ }^{9}$

Robson proposed a simple, reliable and dependable 10 group classification system of LSCS in 2001. WHO on $10^{\text {th }}$ April 2015 recommended RTGCS as an international means of evaluating, observing and comparing LSCS rates. ${ }^{10}$ This system classifies LSCS into one of the ten categories based on the maternal current and past obstetrics history and involves five features for categorizing the cesarean section which are parity, gestation age, fetal presentation, onset of labour and number of fetuses. ${ }^{11}$

The objective of this study was to

1. Analyze the LSCS at KRL Hospital over 6 months period.

2. Categorize them into RTGCS.

3. Recognize the groups contributing substantially to increase the overall LSCS rates.

4. To formulate strategies for reducing these rates.

\section{MATERIAL AND METHODS}

After taking approval from hospital's ethical committee, this cross sectional study was conducted from $1^{\text {st }}$ Nov, 2017 to $30^{\text {th }}$ April, 2018 at Obstetrics and Gynecology department of KRL hospital, Islamabad.

It included all the patients that had Emergency and Elective LSCS during the study period. The exclusion criterion included women who had missing data and thus could not be classified into Robson Ten Group Classification (RTGCS).

A Performa was designed after consulting the senior obstetrician on which details including baseline characteristics (age, parity, onset of labour, previous cesarean section, type of gestation, type of fetal presentation, and gestational age), indication for cesarean, Robson Classification, outcome and whether the patient is an entitled or paying were recorded. The births were distributed into the RTGCS on the basis of pregnancy, maternal past obstetric history and fetal characteristics along with onset of labour whether it was spontaneous, induced, or patient was operated electively without taking labour. Table-l.

\section{RTGC S}

Group 1: Nullipara, single, cephalic, term pregnancy, spontaneous labour

Group 2: Nullipara, single, cephalic, term, induced labour or planned CS

Group 3: Multipara without uterine scar, single, cephalic, term, spontaneous labour

Group 4: Multipara without uterine scar, single, cephalic, term, induced labour or planned CS

Group 5: Multipara with uterine scar, single, cephalic, term Group 6: Nullipara, single, Breech presentation

Group 7: Multipara, single, breech, including previous C-Section

Group 8: Multiple Pregnancy

Group 9: Single, abnormal lie, including previous scar

Group 10: Single, Cephalic, Preterm including previous scar

Table-I. Robsons Ten Group Classification System (RTGCS).

Variables used for this study included.

- Gestational age in weeks calculated from last menstrual cycle and/or ultrasound performed in $1^{\text {st }}$ trimester till 13 weeks.

- Term included gestational age of 37 or more completed weeks

- Multiple pregnancy: woman who had 2 or more fetuses confirmed on ultrasound

- Onset of labour:

1. Spontaneous

2. Induced: use of medication or amniotomy for labour

3. Cesarean Section before labour

- Lie:

1. Longitudinal Lie: either with cephalic or breech presentation. 
2. Abnormal Lie: transverse or oblique presentation.

Data were analysed using statistical package for social sciences (SPSS) version 23. Descriptive statistics were used to calculate frequency and percentages for all the baseline characteristics and LSCS rate including its distribution into RTGCS.

\section{RESULTS}

During the study period, a total of 964 deliveries took place, making a cesarean section rate of $64 \%$ in our setup [Figure-1]. Out of these, Elective LSCS were 403 (65.3\%) and Emergency LSCS were 214 (34.7\%).

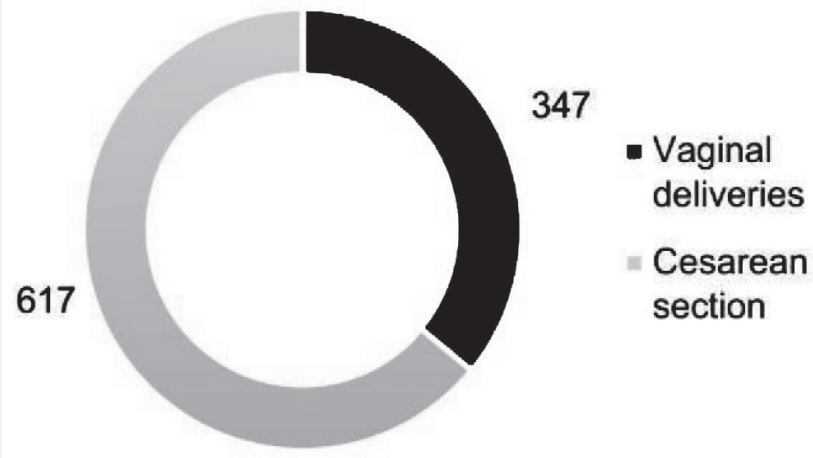

Figure-1. Cesarean section rate.

Majority of the study participants belonged to age group of 20-30 years, were multipara and had term singleton pregnancy with cephalic presentation. More than half were delivered via LSCS before spontaneous onset of labour or labour induction (72\%). Around 42\% patients who underwent LSCS had no history of previous LSCS. Table-II.

Group 5 of RTGC contributed to the overall LSCS rate of $47.5 \%$. (Figure-2) This group was further subdivided into two subgroups for more clarification. Those with previous 1 scar contributed $32.3 \%$ to overall LSCS rate, and this figure was slightly higher than those who had two or more previous scars (25.2\%). The second and the third highest contributor to LSCS rate was the group 2 and group 10 of RTGC contributing to the overall LSCS rate of $18.5 \%$ and $12.8 \%$ respectively. Rest of the groups of RTGC contributed $21.2 \%$ to overall LSCS rate as shown in Figure-2.

\begin{tabular}{|c|c|c|}
\hline Maternal Age & Number (n) & $\begin{array}{c}\text { Percentage } \\
\text { (\%) }\end{array}$ \\
\hline$<20$ & 8 & 1.3 \\
\hline $20-30$ & 421 & 68.2 \\
\hline $30-40$ & 187 & 30.3 \\
\hline$>40$ & 1 & 0.2 \\
\hline \multicolumn{3}{|l|}{ Parity } \\
\hline 0 & 211 & 34.2 \\
\hline $1-3$ & 374 & 60.6 \\
\hline$>3$ & 32 & 5.2 \\
\hline \multicolumn{3}{|l|}{ Onset of Labour } \\
\hline Spontaneous & 108 & 17.5 \\
\hline Induced & 65 & 10.5 \\
\hline C-Section before Labour & 444 & 72.0 \\
\hline \multicolumn{3}{|l|}{ Previous C-Section } \\
\hline None & 263 & 42.6 \\
\hline Previous 1 Scar & 199 & 32.3 \\
\hline$>1$ Scar & 155 & 25.1 \\
\hline \multicolumn{3}{|l|}{ Type of Gestation } \\
\hline Single & 611 & 99 \\
\hline Multiple & 6 & 1 \\
\hline \multicolumn{3}{|l|}{ Type of Fetal Presentation } \\
\hline Cephalic & 583 & 94.5 \\
\hline Breech & 31 & 5 \\
\hline Abnormal Lie & 3 & 0.5 \\
\hline \multicolumn{3}{|l|}{ Gestational Age } \\
\hline Term & 548 & 88.8 \\
\hline Preterm & 69 & 11.2 \\
\hline
\end{tabular}

Table-II. Characteristics of study participants.

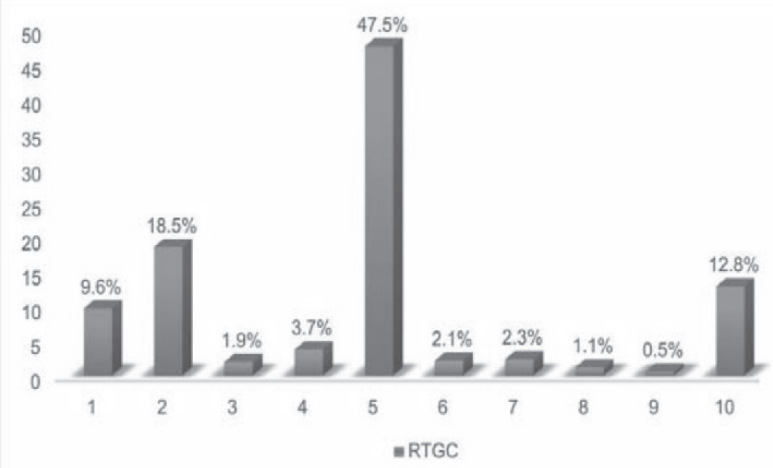

Figure-2. Distribution of LSCS into RTGC.

When cesarean section were analyzed according to their indications, previous scar was the main indication (46.8\%), followed by fetal distress and Cephalopelvic Disproportion (CPD) (11\% and 
8.4\% respectively) as shown in Table-III.

\begin{tabular}{|l|c|c|}
\hline \multicolumn{1}{|c|}{ Indications } & Frequency (n) & Percent (\%) \\
\hline Fetal distress & 68 & 11.0 \\
\hline CPD & 52 & 8.4 \\
\hline $\begin{array}{l}\text { Failed Induction of } \\
\text { labour (IOL) }\end{array}$ & 36 & 5.8 \\
\hline Breech & 32 & 5.2 \\
\hline $\begin{array}{l}\text { Hypertensive disorders } \\
\text { of pregnancy (HDP) }\end{array}$ & 19 & 3.1 \\
\hline Previous Scar & 289 & 46.8 \\
\hline Abruption & 6 & 1.0 \\
\hline Placenta Previa & 6 & 1.0 \\
\hline Multiple Pregnancy & 7 & 1.1 \\
\hline Fetal Macrosomia & 3 & .5 \\
\hline Maternal Request & 15 & 2.4 \\
\hline Failure to progress & 27 & 4.4 \\
\hline Meconium & 18 & 2.9 \\
\hline Others & 39 & 6.3 \\
\hline Total & 617 & 100.0 \\
\hline \multicolumn{1}{|c|}{ Table-III. Distribution of LSCS according to their } \\
\hline
\end{tabular}

Taking the financial aspect into account 399 out of 617 subjects that had LSCS were paying pts as illustrated by Figure-3.

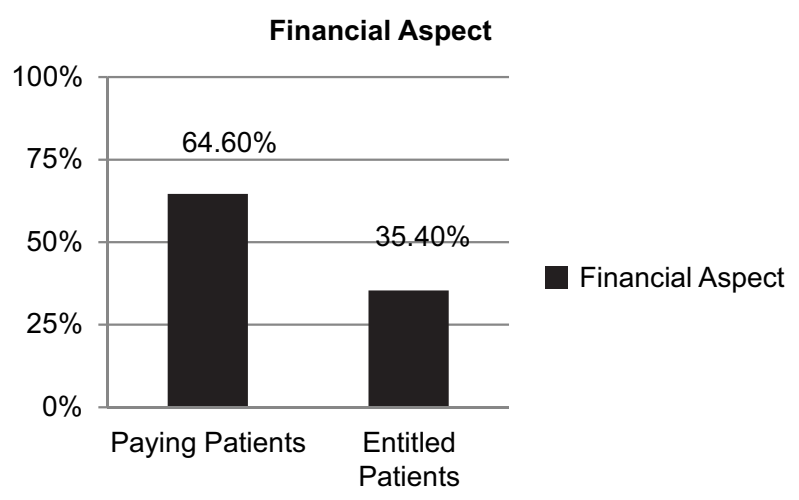

Figure-3. Financial aspect.

\section{DISCUSSION}

Our study has shown alarmingly high LSCS rate of $64 \%$ in our setup which is far higher than $15 \%$ recommended by $\mathrm{WHO}$. The main contributor to increased cesarean section rate was group 5, followed by group 2 and 10 of RTGCS. Previous scar, fetal distress and CPD were the main indications for cesarean section.
In contrast to our LSCS rate of $64 \%$, a survey done by Lumbiganon $\mathrm{P}$ et $\mathrm{al}^{12}$ in Asia the LSCS rate was around $27.3 \%$ but ranging from the lowest of $14.7 \%$ in Cambodia to the highest of $46.2 \%$ in China. Our hospital is a tertiary care hospital with referrals from other less equipped hospitals so our LSCS rate does not represent the rate of general population but that of a tertiary care hospital. This percentage is comparable to other LSCS rates of tertiary care hospitals in Pakistan. Studies done at Isra university hospital Hyderabad Sindh by Haidar $\mathrm{G}$ et al and another conducted by Shamshad et al at Gynae B unit, Ayub Teaching Hospital, Abbottabad reported caesarean section rates of $67.7 \%$ and $45.1 \%{ }^{13,14}$

The LSCS rate of CMH Hyderabad was $41.96 \%$ in a study published in $2016 .{ }^{15} \mathrm{Amin} \mathrm{N}$ et al reported LSCS rate of $42.6 \%$ in $\mathrm{CMH}$ Attock ${ }^{16}$ while $\mathrm{CMH}$ Rawalpindi had a LSCS rate of $56 \%$ in a study done by Jabeen $\mathrm{J}$ et al. ${ }^{17}$ In contrast to these rates a study published in 2015 of Gynecology unit-A of Lady Reading Hospital Peshawar reported LSCS rate of $21.7 \%$ in $2010-2011 .{ }^{18}$

This increasing trend of cesarean section has many implications like low threshold for labour pains, less expertise of instrumental deliveries, malpractice concern, fear of trial of labour after cesarean (TOLAC), excessive use of CTG, labour inductions without indication, maternal request etc.

In this study, group 5, 2 and 10 contributed most to the overall LSCS rate with the leading group being group 5 . While in the studies conducted by Bolognani CV et al. and Brennan DJ et al. the main groups contributing to the cesarean section rate were $5,1,2 . .^{10,19}$ In a study at Singapore by Tan JKH et al, the main contributor to the overall LSCS rate was group 5 followed by Group 2 and Group 10 each contributing 25.9\%, 18\% and $16.1 \%$ respectively. ${ }^{20}$ These results are in comparison with our study which shows that VBAC is not being done from fear of uterine rupture and women are opting for elective repeat LSCS after one scar. 
In the region of subcontinent there is a trend of marriage at an early age and lack of contraceptive practices along with low education which has led to childbirth at an early age. Our study participants were mainly therefore between 20-30 yrs of age which is the same age group in other studies which had showed high LSCS rate. ${ }^{21}$ In contrast to this, Parrish KM et al. in his study conducted at USA reported the mean age of participants to be more then 40 years which shows the trends of delayed marriage and late childbirth seen in that region. ${ }^{22}$

Financial incentives such as higher payments for LSCS and specifics for reimbursement arrangements seem to influence the clinical decision of as to whether to perform LSCS or not.

Previous scar and fetal distress has been reported as the main indications by studies conducted by Rahman $\mathrm{H}$ et al. and Yadav $\mathrm{S}$ et al.$^{8,23}$ which is the same as in our study.

In group 1 and 2 consisting of nulliparous women with term, single, cephalic presentation in spontaneous labour, and those induced or having cesarean before labour, the main indications for LSCS were fetal distress, failure to progress, failed IOL and maternal request. The use of partogram for monitoring of labour ${ }^{24}$ and reassessing the indication of intrapartum LSCS ${ }^{25}$ can help reduce LSCS rate in these groups. Women admitted to indoor department when not in active labour, have a $15.8 \%$ probability of having a cesarean section which is 2.5 times at higher risk. ${ }^{26}$ Shrewd assessment for IOL considering the cervical conditions and reconsidering the indications of $1 \mathrm{LL}^{27}$, waiting for natural labour to begin where possible and not embarking on cesarean section without a solid indication is the key in reducing the primary cesarean section rate.

Group 3 contributed $1.9 \%$ to the overall LSCS rate in our study which is within the maximum $2 \%$ cesarean section rate expected in this group. ${ }^{28} \mathrm{As}$ such no intervention is required to further reduce the LSCS rate in this group.

For group 4 multiparous women; avoiding unnecessary IOL without indications, admissions of women who aren't in active labour, expertise in maintaining and interpreting partogram, reassessing for intrapartum cesarean indication and avoiding the primary cesarean section at all possible costs remain the specific goals for this group.

In our study Group 5 consisting of women with previous scar had the maximum rate. The aim for reducing the rate for this group should be, to give TOLAC instead of considering elective repeat LSCS. $^{29}$

Group 6, 7 of RTGCS consists of nullipara and multipara with breech presentation and Group 9 include transverse or oblique lie. The results of Term Breech Trial which were published in 2000 led to rapidly increased LSCS rates for breech presentation. ${ }^{30}$ The contribution of these groups to the overall LSCS rate remained low. To further reduce the rate in these groups, the technique of external cephalic version and method of breech vaginal delivery should be mastered and applied in term pregnancies with abnormal lie.

Group 8 of RTGCS comprises of multiple pregnancy. The mode of delivery is driven by the presentation of the first baby. Amongst multiple gestations, diachorionic diamniotic twins with first cephalic presentation can be delivered vaginally. Nothing much can be done in higher order gestations and even in twins where first twin is having an abnormal lie.

Surprisingly Group 10 emerged as the third largest contributor to overall cesarean rate in our study. All singleton, cephalic, preterm pregnancies were included in this group. Its representation in the overall LSCS rate was $12.8 \%$. Cesarean sections in this group were usually performed due to maternal and obstetric complications such as HDP, decreased fetal movements, fetal distress, intrauterine growth restrictions, preterm prelabour rupture of membranes, antepartum hemorrhage and scar tenderness. This high percentage may be due to the fact that this is a tertiary care unit with availability of ventilator support for newborn resulting in referrals and in utero transfer of high 
risk cases to our hospital.

\section{CONCLUSION}

In conclusion RTGCS is very useful in auditing the cesarean section rate and in categorizing the cesareans to different groups. It also helps in identifying the particular groups which are contributing to high cesarean rates. Effort can then be directed towards those groups, strategies can be devised and policies and practices modified to help reduce the LSCS rate until we achieve the ideal rate recommended by $\mathrm{WHO}$.

\section{Copyright@ 16 July, 2019.}

\section{REFERENCES}

1. William JW. A criticism of certain tendencies in American obstetrics NY. State J Med. 1922; 22:493-9.

2. US Department of Health and Human Services. National Institutes of Health. Cesarean childbirth. Publication no 82-2067; 1981.

3. US Department of Health and Human Services. Healthy people 2000: National health promotion and disease prevention objectives. In Healthy people 2000: National health promotion and disease prevention objectives 1991. US Government Printing Office.

4. World Health Organization: Appropriate technology for birth. Lancet. 1985; 2(8452):436-7.

5. National Institutes of Health state-of-the- science conference statement (2006) Caesarean delivery on maternal request. Obstet Gynecol 107:1386-97.

6. Hamilton BE, Hoyert DL, Martin JA, Strobino DM, Guyer B. Annual summary of vital statistics: 2010-2011. Pediatrics. 2013: 131:548-58.

7. Barber EL, Lundsberg LS, Belanger K, Pettker CM, Funai $\mathrm{EF}$, et al. Indications contributing to the increasing cesarean delivery rate. Obstet Gynecol. 2011; 118:2938.

8. Rahman $H$, Pradhan $D$. Rising trends and changed indications of caesarean sections in Sikkim, India: cause for concern? Int J Reprod Contracept Obstet Gynecol. 2016; 5:1851-6.

9. Betran AP, Vindevoghel N, Souza JP, Guelmezoglu AM, Torloni MR. A systematic review of the Robson classification for caesarean section: what works, doesn't work and how to improve it. PloS ONE. 2014; 9(6):e97769.
10. Bolognani CV, Reis LB, Dias A, Calderon ID. Robson 10-groups classification system to access C-section in two public hospitals of the Federal District/Brazil. PloS one. 2018 Feb 20; 13(2):e0192997.

11. Tapia V, Betran AP, Gonzales GF. Caesarean section in Peru: Analysis of trends using the robson classification system. PloS one. 2016 Feb 3; 11(2): 0148138.

12. Lumbiganon P, Laopaiboon M, Gülmezoglu AM, Souza JP, Taneepanichskul S, et al. Method of delivery and pregnancy outcomes in Asia: The WHO global survey on maternal and perinatal health 2007-08. Lancet. 2010; 375(9713):490-9.

13. Haider G, Zehra N, Munir AA, Haider A. Frequency and indications of cesarean section in a tertiary care hospital. Pak J Med Sci. 2009; 25(5):791-6.

14. Shamshad. Factors leading to increased caesarean section rate. Gomal J Med Sci: 2008: (1): 1-5.

15. Baig JR, Jamal MM, Ashfaq T. A two year analysis of cesarean delivery at CMH Hyderabad. Pak Armed Forces Med J. 2016; 66(1):25-29.

16. Amin N, Malik NJ. Role of antenatal checkup on caesarean section rate - study at CMH Attock. Pak Armed Forces Med J. 2017; 67 (4): 599-603.

17. Jabeen $\mathrm{J}$, Mansoor MH, Mansoor A. Analysis of indications of caesarean sections. Journal of Rawalpindi Medical College (JRMC). 2013; 17(1):101103.

18. Naeem M, Khan MZ, Abbas SH, Khan A, Adil M, Khan MU. Rate and Indication of elective and emergency cesarean section: A study in a Tertiary Care Hospital of Peshawar. J Ayub Med Coll Abbottabad. 2015; 27:151-4.

19. Brennan DJ, Robson MS, Murphy M, O'Herlihy Comparative analysis of international cesarean delivery rates using 10-group classification identifies significant variation in spontaneous labor. $\mathrm{Am} \mathrm{J}$ Obstet Gynecol. 2009; 201:308.e1-308.e8.

20. Tan JKH, Tan EL, Kanagalingan D, et al. Rational dissection of a high institutional cesarean section rate: An analysis using the Robson Ten Group Classification System. J Obstet Gynaecol Res. 2015; 41(4):534-9.

21. Samal R, Palai P, Ghose S. Clinical study of primary caesarean section in multiparous women in a tertiary care hospital. Int J Reprod Contracept Obstet Gynecol. 2016May; 5(5):1506-9. 
22. Parrish KM, Holt VL, Earterling TR, et al. Effect of changes in maternal age, parity and birth weight distribution on primary caesarean delivery rates. Journal of American Medical Association.1994; 271(3):1001-15.

23. Yadav S, Kaur S, Yadav SS, et al. Analysis of caesarean rate, indications and complications: Review from medical college Ambala, Haryana, India. Int J Reprod Contracept Obstet Gynecol.

24. World Health Organization partograph in management of labour. World Health Organization Maternal Health and Safe Motherhood Programme. Lancet. 1994; 343: 1399-404.

25. Althabe F, Belizan JM, Wang PH, et al. Mandatory second opinion to reduce rates of unnecessary caesarean sections in Latin America: A cluster randomized controlled trial. Lancet. 2004; 363: 193440.
26. Svelato A, Di Tommaso $M$, Spinoso $R$, et al. The reduction of first cesarean sections: $A$ cultural issue. Acta Obstet Gynecol Scand. 2016 Aug 12.

27. Le Ray C, Blondel B, Prunet C, et al. Stabilizing the caesarean rate: Which target population? BJOG. 2015; 122:606-9.

28. Robson MS. Can we reduce the caesarean section rate? Best Pract Clin Obstet Gynaecol. 2001; 15:17994.

29. ACOG Practice Bulletin No 115: Vaginal birth after previous cesarean delivery. Obstet Gynecol. 2010; 116: 450-63.

30. Hannah ME, Hannah WJ, Hewson SA, et al. Term Breech Trial Collaborative Group. Planned caesarean section versus planned vaginal birth for breech presentation at term: A randomized multicentre trial. Lancet 2000; 356:1375-83.

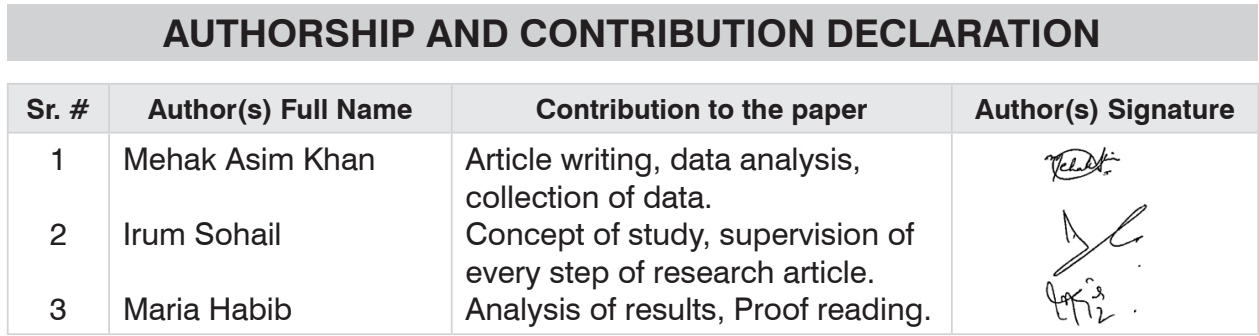

